\title{
BMJ Open Why do patients seek primary medical care in emergency departments? An ethnographic exploration of access to general practice
}

\author{
Fiona MacKichan, ${ }^{1}$ Emer Brangan, ${ }^{1}$ Lesley Wye, ${ }^{1}$ Kath Checkland, ${ }^{2}$ \\ Daniel Lasserson, ${ }^{3}$ Alyson Huntley, ${ }^{1}$ Richard Morris, ${ }^{1}$ Peter Tammes, ${ }^{1}$ \\ Chris Salisbury, ${ }^{1}$ Sarah Purdy ${ }^{1}$
}

To cite: MacKichan $\mathrm{F}$, Brangan E, Wye L, et al. Why do patients seek primary medical care in emergency departments? An ethnographic exploration of access to general practice. BMJ Open 2017;7:e013816. doi:10.1136/ bmjopen-2016-013816

Received 9 August 2016 Revised 7 February 2017 Accepted 13 March 2017

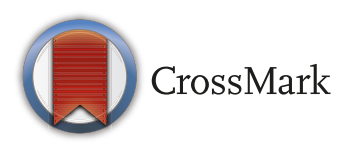

${ }^{1}$ School of Social and Community Medicine, University of Bristol, Bristol, UK

${ }^{2}$ Centre for Primary Care, Institute of Population Health, University of Manchester, Manchester, UK

${ }^{3}$ Nuffield Department of Medicine, Oxford University Hospitals NHS Foundation Trust, Oxford, England

Correspondence to Dr Fiona MacKichan; fiona mackichan@bristol.ac.uk

\section{ABSTRACT}

Objectives To describe how processes of primary care access influence decisions to seek help at the emergency department (ED).

Design Ethnographic case study combining nonparticipant observation, informal and formal interviewing. Setting Six general practitioner (GP) practices located in three commissioning organisations in England.

Participants and methods Reception areas at each practice were observed over the course of a working week (73hours in total). Practice documents were collected and clinical and non-clinical staff were interviewed $(n=19)$. Patients with recent ED use, or a carer if aged 16 and under, were interviewed $(n=29)$.

Results Past experience of accessing GP care recursively informed patient decisions about where to seek urgent care, and difficulties with access were implicit in patient accounts of ED use. GP practices had complicated, changeable systems for appointments. This made navigating appointment booking difficult for patients and reception staff, and engendered a mistrust of the system. Increasingly, the telephone was the instrument of demand management, but there were unintended consequences for access. Some patient groups, such as those with English as an additional language, were particularly disadvantaged, and the varying patient and staff semantic of words like 'urgent' and 'emergency' was exacerbated during telephone interactions. Poor integration between in-hours and out-of-hours care and patient perceptions of the quality of care accessible at their GP practice also informed ED use.

Conclusions This study provides important insight into the implicit role of primary care access on the use of ED. Discourses around 'inappropriate' patient demand neglect to recognise that decisions about where to seek urgent care are based on experiential knowledge. Simply speeding up access to primary care or increasing its volume is unlikely to alleviate rising ED use. Systems for accessing care need to be transparent, perceptibly fair and appropriate to the needs of diverse patient groups.

\section{BACKGROUND}

The number of people seeking urgent healthcare in emergency departments (EDs) has
Strengths and limitations of this study

- This in-depth qualitative study helps to explain how interactions in primary health care influence patients' help seeking behaviour and decisions to attend the ED.

- Our analysis draws attention to modifiable features of primary health care that have the potential to help reduce $\mathrm{ED}$ use.

- Patients and carers were invited to participate in the study via their own GP practice. This means that those participating may not be representative of all those self-referring to the ED, and their interviews may be influenced by the method of recruitment (eg, participants may either have 'an axe to grind' or be reluctant to criticise)

risen to record levels in the National Health Service in England, with over 2 million monthly attendances recorded for the first time in March 2016. ${ }^{1}$ This has had significant implications for delivering national urgent care policy, as the increasing number of attendances has been associated with a continuing decrease in performance of the national '4-hour standard', whereby EDs should assess, diagnose, treat and either discharge patients home or admit them to hospital teams within 4 hours of arrival at the ED. ${ }^{1}$ Given that a significant proportion of ED attendances, $62.8 \%$ in $2014-15,{ }^{2}$ are self-referred (patients choose to attend ED, rather than being referred by a healthcare provider), are discharged with 'advice only' (treatment in an acute hospital setting was not required) and that ED attendances peak during the working day on a Monday, ${ }^{34}$ it is presumed that better access to primary care will relieve pressure on EDs. This in turn could improve the performance of EDs in the NHS and help them to deliver the 4-hour 
standard by reducing pressure on fixed resources of staff, clinical space and diagnostic support services.

Given this, and that access is considered to be a central feature of high-quality healthcare, ${ }^{5}$ it seems evident that initiatives to improve primary care access are of value. Rapid access to primary healthcare in England is incentivised, with reward based on performance in the annual patient survey in primary care. (ie, patient reports of satisfaction with speed of access). In response to this, many GP practices have sought to implement the 'advanced access' model that has been adopted effectively in the USA, ${ }^{67}$ and impetus to increase the volume of GP appointments through extending access to weekends and evenings, for example, has grown. Criticism of these approaches has included that the emphasis on speed of access has been to the neglect of other, important, dimensions of access, for example access to choice in appointment type or provider, and physical access including availability of GPs and design of premises, ${ }^{89}$ and that they oversimplify the problem. There have been conceptual and practical barriers to implementing change, both relating to advanced access ${ }^{7}$ and increasing the volume of GP access, with initiatives such as the Greater Manchester Primary Care Demonstrator Evaluation failing to provide convincing evidence that increasing the volume of primary care access leads to a reduction in ED use. ${ }^{10-12}$

The factors that determine the choice of location of first healthcare contact for urgent problems are complex. A review examining influences on ED attendance across different healthcare systems found a differential impact of access to primary care, although some studies were limited by their methods of analysis. A review examining influences on ED attendance across different health care systems found a differential impact of access to primary care, however some studies were limited by only reporting univariable analysis, which failed to allow for potential confounding factors. ${ }^{13}$ Recent quantitative analyses of the relationship between access measures in primary care and ED attendance in England have found that even after adjustment for potential confounders, patient reports of poorer access to primary care were associated with increased ED attendance. ${ }^{3}{ }^{13-17}$ Qualitative studies of ED use often focus on 'appropriateness' of use and patient motivations for location of care-seeking, highlighting discrepancies between patient and provider views. ${ }^{18-24}$ Some qualitative data on ED use demonstrate the complexity of decisions about where to seek care, framing demand as rational. ${ }^{20}$

In order to understand in more detail how the processes of primary care access can affect the decisions made by patients over their choice of first contact healthcare provision for urgent problems, we designed an ethnographic study at the critical interface between the community and its primary care practice- the reception area and its team that implement the process of access to clinicians. Our objective was to provide a nuanced account of how interactions that take place when patients seek urgent primary healthcare might inform decisions to seek help at the ED.
METHODS

\section{Design}

We conducted an ethnographic case study of six general practices in 2012-15. Multiple methods were employed to achieve detailed and contextual insight, including non-participant observation, individual interviews and analysis of documents. The ethnography research team comprised three social scientists (EB, FM, LW) and an academic GP (KC). Ethical approval was given by the National Research Ethics Committee West Midlands (Coventry and Warwick), study reference 13/VM/0241.

\section{Setting and sampling}

We chose six GP practices across three commissioning organisations (clinical commissioning groups). Using routine data from 3 years (2009-2010, 20102011 and 2011-2012), GP practices within each commissioning area were stratified into quintiles by rate of ED use and unplanned hospital admissions. These data were scrutinised to identify potential cases, for example, practices that seemed to have lower unscheduled care use than might be expected given population characteristics (such as high levels of deprivation, large older population), pairs of practices with relevant shared characteristics but very different rates of unscheduled care use, and practices that had moved significantly between quintiles. Selected practices varied in features such as size and diversity of the patient population, staffing and area deprivation (table 1 ).

A sample of patients/carers with recent experience of ED use were invited to interview. Participating practices generated anonymised lists of patients with recent $(\leq 3$ months) ED use. Those patients who had self-referred to the $\mathrm{ED}$, who attended the ED during GP practice opening hours, who had no investigations while at the ED and/ or who were discharged with 'advice/guidance only' were approached first, as the potential to have had needs met in primary healthcare was considered to be higher in this group. A range of clinical and non-clinical staff at participating practices were also invited to interview by the practice's research contact or during observation by the researcher. Informal interviews supplemented recorded staff interviews.

\section{Data collection}

Non-participant observation took place between October 2013 and July 2014. Consent was sought at the practice level for observations. Observation took place in the reception and 'back office' administrative areas, as we wanted to look at interactions with patients, between practice staff and between practice staff and other healthcare professionals to gain insight into practice factors and how these might influence patients' care-seeking. The observing researcher wrote field notes on a notebook during events or shortly afterwards. Much of what was observed was telephone interactions, and where necessary these were followed by informal discussion with staff to gain clarification. Notes were taken in informal 


\begin{tabular}{llllll}
\hline & & $\begin{array}{l}\text { List size as } \\
\text { percentage of } \\
\text { commissioning } \\
\text { area average (\%) }\end{array}$ & $\begin{array}{l}\text { Quintile on index of } \\
\text { multiple deprivation }\end{array}$ & $\begin{array}{l}\text { Full-time } \\
\text { equivalent } \\
\text { GPs/1000 patients } \\
\text { (commissioning } \\
\text { area average) }\end{array}$ & $\begin{array}{l}\text { Observation period (total } \\
\text { hours) }\end{array}$ \\
\hline 1 & 1 & 67.9 & Second most deprived & $0.476(0.54)$ & October/November 2013 (18) \\
\hline 2 & 1 & 139.5 & Second most deprived & $0.52(0.54)$ & February 2014; May 2014 (14) \\
\hline 3 & 1 & 58 & Most deprived & $0.62(0.54)$ & February 2014; May 2014 (14) \\
\hline 4 & 2 & 209.6 & Fourth least deprived & $0.5(0.6)$ & June 2014 (10) \\
\hline 5 & 2 & 225.6 & Second least deprived & $0.51(0.6)$ & June 2014 (9) \\
\hline 6 & 3 & 197.4 & Second most deprived & $0.54(0.57)$ & July 2014 (8) \\
\hline
\end{tabular}

GP, general practitioner.

discussions and detail added immediately afterwards, as necessary. The observer also collected relevant documents (eg, policies/guidelines for staff, meeting notes, patient information leaflets).

Staff interviews sought to get insight into their experiences of patients seeking urgent care and views of their workplace's policies and practices around access. In some instances the invitation was issued to all staff at a practice meeting or in staff pigeonholes, and the staff then approached the researcher to express interest. At other practices individual staff were identified and approached by the practice contact (eg, research lead). The process was iterative, and some potential interviewees were identified by the researcher as a result of data collection. For example, at one practice, patient and staff interviewed frequently mentioned a particular GP who seemed to be the preferred GP for patients with higher rates of ED attendance, and so this person was approached and subsequently interviewed. Interviews were audio-recorded with written consent and a topic guide was employed to facilitate discussion. Topic guides for staff and patient interviews were developed by the team using a published systematic review $^{14}$ and a scoping review of qualitative literature to identify areas to probe. The guides contained a small number of open questions with a list of prompts/ probes to facilitate data collection.

Patient/carer interviews sought to understand pathways to the ED and experiences and views of the practice. Identified patients (or carers for patients aged 16 and under) were sent invitation letters by their GP practice, with a reply slip to be returned directly to the researcher. As with staff interviews, patient/carer interviews were audio-recorded with participants' consent and a topic guide was used. The topic guide had two parts, the first invited participants to tell the story of their recent ED use (with various probes to elicit detail, from first signs / symptoms to what has happened since the index ED use), and the second invited participants to share their views of their GP practice, with a broad question, "tell me about your GP practice", and prompts to elicit a full picture.

\section{Analysis}

Field notes and documentary analysis were transcribed into MS Word by EB. A structure to the typed field notes was developed from the first two practices, which was applied to subsequent practices. This included information about the practice (population, staffing, summary of results from the most recent GP patient survey, etc), description of the practice context, a diagram of the practice layout and a description of observed interactions. The field notes were read by EB (with double coding of a selection by LW) to identify themes specific to the practice and also cross-cutting themes (eg, 'Being dealt with/ seen in a timely manner at reception or for booked care', and 'unscheduled secondary care-specific references'), and a description of these was written by EB. Interviews were transcribed verbatim by a professional transcriber, and then checked for accuracy and anonymised by FM. Transcripts were uploaded to NVivo 9. FM wrote an interpretive narrative of each transcript and then integrated these in a descriptive account for each practice that included observational field note data and interview data. The ethnography team met monthly to discuss the ongoing analysis and data collection. This included reviewing and coding raw data (a selection of transcripts and observational field notes) and interpreting descriptive accounts.

\section{Practice summaries and integration}

Field notes and interview descriptive accounts for each practice were reviewed by FM. Overarching themes relating to how interactions relating to urgent care at each practice influenced ED use were identified, and these formed the structure of a case summary for each practice. Each summary was reviewed by the ethnography research team and key findings were fed back to the wider research team for discussion. All six summaries were then evaluated together to identify key features of primary healthcare that influence use of unscheduled secondary care.

The results presented here show how dimensions of access to primary healthcare are implicit factors in 


\begin{tabular}{|c|c|c|}
\hline Practice & Pseudonym & Role in practice \\
\hline \multirow[t]{4}{*}{1} & Elizabeth & Lead GP \\
\hline & James & Reception/administration \\
\hline & Sally & Reception/administration \\
\hline & Michelle & Reception/healthcare assistant \\
\hline \multirow[t]{3}{*}{2} & Charlotte & Reception and access manager \\
\hline & Emily & GP \\
\hline & Olivia & Lead GP \\
\hline \multirow[t]{3}{*}{3} & Matthew & GP \\
\hline & Connie & Office manager \\
\hline & Paula & Medical secretary/receptionist \\
\hline \multirow[t]{3}{*}{4} & Becky & Audit controller \\
\hline & Linda & Reception Manager \\
\hline & Bronwyn & GP \\
\hline \multirow[t]{3}{*}{5} & Laura & Patient services manager \\
\hline & John & GP \\
\hline & Lindsay & Nurse practitioner/manager \\
\hline \multirow[t]{3}{*}{6} & Alexander & Reception/administration \\
\hline & Leah & Quality improvement facilitator \\
\hline & Sadiq & GP \\
\hline
\end{tabular}

GP, general practitioner.

patients' decisions to attend the ED. Results are illustrated with interviewee quotes and extracts from observational field notes; pseudonyms are used for all participants.

\section{RESULTS}

Seventy-three hours of observation across six practices were recorded in total (table 1). Nineteen members of staff were interviewed (table 2): seven GPs, seven reception staff, four managers and one nurse practitioner. Twenty patients and 9 parents/carers were interviewed (table 3), 17 in their own homes and 12 by telephone. Ten patient interviewees spoke English as an additional language; none requested a translator.

Although features of general practice were not usually explicitly stated by patients as factors in seeking help at the ED, they were implicit in patient accounts and were observed to be important determinants of patient behaviour during fieldwork.

\section{Intricate appointment systems}

Highly complex appointments systems that had evolved incrementally over time were typical. Both patients and reception staff found these obscure and hard to navigate; patients mistrusted them, and their operation was affected by the skills and experience of reception staff. Each practice had a unique appointment system, with a range of appointment categories and ways of allocating appointments. Nurse or GP-led telephone triage was used by several practices, and two ( 5 and 6 ) encouraged patients to see the same doctor each time. A general shift towards same-day appointments and telephone appointments/telephone triage was evident.

Patient/carer interviews revealed a degree of suspicion among patients, and this was recognised by reception staff: "they [patients] think you're hiding appointments" (Sally, receptionist, GP practice 1). At practice 2, reception manager Charlotte commented: "some patients sit in the reception waiting room to wait for the phone call. There's a perception that if they do that then they might be seen." Factors contributing to a lack of confidence in access systems included ongoing incremental changes to systems that were not clearly communicated to patients and a reliance on the telephone for access. Telephone systems could be overloaded at the start of the day when same-day appointments were generally allocated and patients reported getting 'mixed messages':

On the Friday I rang and they said, "You'll have to ring back on Monday." And I said, "Well I need to speak to a doctor as well [as having a face to face consultation]," and they said, "That'll be next Thursday." I said, "What, a week to speak to a doctor?" But then I rang again on the Monday and somebody said, "Right, somebody will phone you back in two hours." (Mo, patient, GP practice 2)

Complex appointment system meant reception staff have an important role in facilitating access. Receptionists at all practices engaged to some extent in patient triage, for example by determining the level of urgency in appointment requests. Observation of newly appointed staff dealing with appointment requests suggested that knowledge of how the system worked was often tacit and uncodified (box 1).

Reception staff were aware of how experience mattered: "I wouldn't say everybody would know what to look for. I think it's a trained eye" (Paula, receptionist, GP practice 3), and Alexander, a receptionist at GP practice 6 describes how "you have to kind of read between the lines most of the time" when eliciting information from patients. When asked about how he would decide whether to pass a call to a nurse practitioner or a GP, he said, "I would base it on the symptoms. I think, you know, having worked here this long I have a good understanding of what the nurse practitioners are capable of."

For patients, reception staff were seen as 'gatekeepers', "If you call you speak to a receptionist, you feel like you've got to get past that first, you know, enough to get an appointment" (Grace, patient, GP practice 4). As discussed earlier, patients might feel that reception staff were obstructing access. However, observation suggested rather that staff used the system flexibly to facilitate access. In informal discussion, Rhona, a receptionist at GP practice 1, told us, "Sometimes we can manipulate the system, but we try to stick to the appointments."

Each practice's system reflected its patient population and its priorities. Practice 2, with a significant Muslim population, introduced a Saturday morning clinic to 
Table 3 Patient/carer interviews

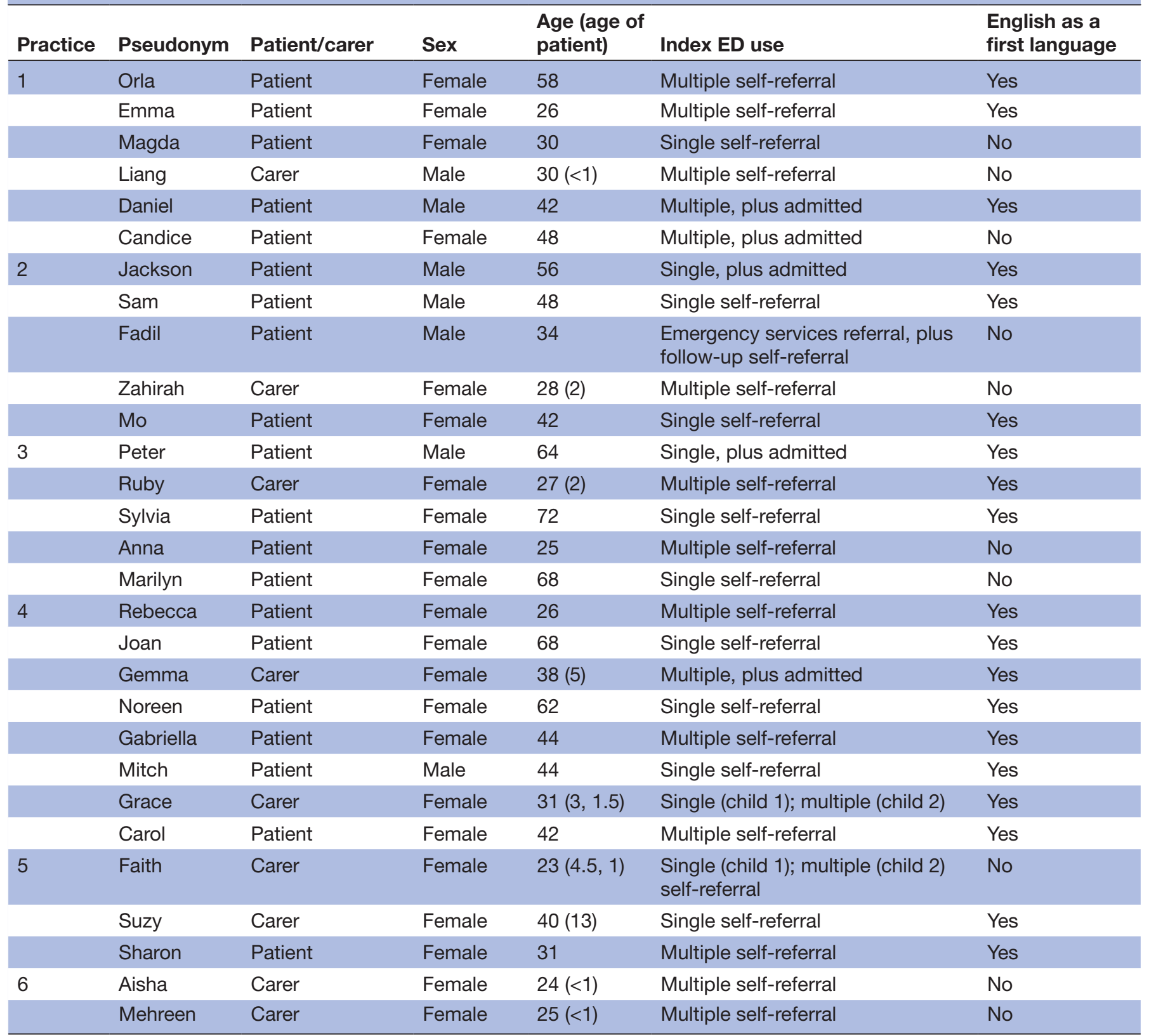

ED, emergency department.

accommodate patients who couldn't attend the practice on Friday afternoons, whereas practice 1 was set up specifically to enhance access for 'hard to reach groups'. In practice 1 there was a significant focus on facilitating access for patients with drug and alcohol misuse problems or who were homeless (box 2).

In contrast, this flexible and accommodating approach was not generally applied to patients who had English as an additional language at practice 1 . Reception staff experienced language barriers as problematic and disruptive:

We just have to try and work out what it is they're saying and we have to try and make ourselves understood and it is difficult. It's really difficult. There's no system currently in place to alleviate that and it's tricky to see how you could. I mean unless you have a member of staff, every single of member speaking a language... And those conversations take ages because you can't hang up if you don't understand. (James, receptionist, GP practice 1)

As discussed earlier, the intricate systems we observed had generally arisen out of an ongoing process of monitoring and adjustment, "we're constantly looking at the appointment system to see what the balance of book on the day and book in advance is" (Bronwyn, GP at GP Practice 5). For example, practice 2 changed the number of telephone triage slots each week based on the previous 3 weeks' use. Two practices ( 5 and 6 ) were particularly focused on increasing efficiency by monitoring and 
Box 1 Reception staff skills and knowledge (observation field notes)

Practice 4: One Monday morning in particular there were regular discussions about whether a doctor or a nurse was more appropriate, with receptionists sometimes seeming to be seeking to 'sell' nurses to patients by stating that they could prescribe, and that the wait might be shorter (experienced receptionist Linda, "Would you be happy to see a nurse practitioner? She can prescribe."). The new receptionist Beth was observed routinely asking patients if they needed to see a nurse or a doctor ("Do you need to see a doctor or can you see a nurse?"), effectively placing the responsibility on the patient to choose with the implied assumption that they knew who could deal with what Some patients did know - for example, they had past experience of a similar problem and knew it was unlikely to be something the nurse would be able to prescribe for. Others were more uncertain at being allocated this self-triage role by Beth.

09:01—A man with a young boy is being served by Beth. He says he was told on the phone to come down, but there are now no appointments left with the person he wanted to see. Linda joins Beth and tells the man that the boy will be seen. She asks what the problem is. He says tonsillitis and Linda suggests that they see the nurse practitioner.

10:04-Beth is still asking people if the nurse can help. They sometimes respond with a description of the problem they are here about; they want her to triage/make the decision. She puts the man who is currently at the desk down for the nurse. His first language is not English and he continues trying to explain something to her. The more experienced receptionist, Linda, provided guidance and advice, helping the patient and steering them towards what she saw as the best option.

changing their system. At practice 5, Practice Manager Graham described how appointments were allocated based on historical data. For example, Mondays were busy, and so had the highest number of emergency slots. Waiting times for specific doctors were also reviewed,

\section{Box 2 Practice 1 - Meeting the needs of specific patient} populations

Strategies exist to facilitate access to services, for example outreach work, maintaining good relationships with external groups such as homelessness charities, and use of the patient warning system: "With particularly vulnerable patients the GP will put a patient warning on... It will pop up a window in the middle of your screen which you have to acknowledge before you can carry on. So it's usually things like 'Prioritise appointments with Dr Elizabeth' or permission to use embargo slots for this patient." (James, reception)

The high proportion of these vulnerable patients on the list was often mentioned in interviews, with reception staff demonstrating awareness of their needs and life contexts, "life's so chaotic anyway that they don't remember... we do have to bear in mind that they're not going by times and dates" (Michelle, reception/healthcare assistant). Observations showed that reception staff were familiar with dealing with drug or alcohol-dependent and homeless patients and dealt with them calmly and patiently. Sometimes patients were provided with appointments or prescriptions outside of normal procedures due to a concern that they would 'kick off' otherwise. and patients were switched between doctors' lists if waits exceeded 5 days. Practice 6 was unusual in adapting procedures for specific patient populations. For example, they found that telephone triage of young children generally led to face-to-face appointments, so they decided to offer appointments for young children without the need for triage. Alexander (receptionist) notes that the appointment system "has been tweaked so much over the years." However, this approach of incremental and reactive system changes-tweaking things—could be problematic for patients. One patient interviewed, Aisha, said, "Do you know, with appointment it used to be easy? You'd book your appointment and then you'd go in to the doctor." Similar feelings were echoed by patients at other practices:

I tried to register again [for the booking system] and it was like, "We're not using this system now; we're using a different system." You try and register, and then I didn't ever receive like a confirmation email back and I just kind of gave up and thought, "Whatever, I'll just leave it." (Grace, patient at GP practice 4)

\section{Appointment availability}

Most practices had incrementally increased same-day appointments, telephone triage or telephone consultation slots. Staff were generally positive about telephone access/triage, as it reduced demand for face-to-face appointments and meant that there was always something to offer patients, even if this was simply an instruction to call back the next morning to access triage slots. This approach was common at practice 1 , where staff reported that that the triage list fills up within minutes:

There's six appointment slots. You never ever book into triage except on the morning. It's electronically locked until 8.00. People phone up at 8.00 , so the phones usually go berserk. (James, receptionist)

Staff felt a same day service was aligned this with patient demand, "I think people will want to see somebody now" (Laura, Patient Services Manager at GP Practice 5). Patients were generally very mindful of this morning rush, and described spending a lot of time seeking an appointment, "they tell you to keep on, and sometimes you might get through after, say after 10 o'clock" (Sylvia, Patient at GP Practice 3); "some people miss out "cos there are so many people calling at the same time" (Faith, patient at GP Practice 5). Most practices released same-day appointments prior to the practice physically opening, favouring those with access to/preference for the telephone. Some features of appointment systems were opaque to patients; for example, patients from GP practice 1 were rarely aware that additional appointments were released in the afternoon. The existence of different types of appointment could be bewildering: 
Box 3 Reliance on telephone triage (observation field notes)

At practice 2, the vast majority of people who contacted the surgery seeking a GP appointment were told that there were no face-to-face GP appointments at all available for them to book, and were either instructed to call back on another day to try and book a newly released appointment a week in advance then, or if they could not wait this long they were offered a call back from the on-call doctor today. It seemed that many patients who would have been satisfied to book an appointment in a few days' time were ending up on the same-day triage list because this was not an option.

Monday 08:47: Receptionist Donna, "At the moment all appointments booked for next Monday." "If you ring up today you basically get an appointment for next Monday, but they're all gone. If you need today I can put you down for a call." Patient asks about appointments. "No, nothing, tomorrow release more appointments which are for next Tuesday." Donna offers a call today again. Ends up booking patient into a telephone slot on Thursday after 12:30. Donna's next call: "We don't, they're all gone now." "OK sorry about that, bye, bye."

I am not very happy about this part of it. I could go down there now, drive down there and say I'd like to see Dr X or any of the doctors in our practice... "Right um there's no appointments available until next week. But if you would like to ring at eight o'clock in the morning, tomorrow morning, we will fit you in as an emergency and you will see a doctor." (Peter, patient, GP practice 3)

The provision of a same-day appointments or telephone triage was arguably at the cost of routine appointments (box 3). Connie, Office Manager at Practice 3, described this gap, "the issue normally is when they want an appointment sort of that week, the following day, or the following two days". Demand for routine appointments was difficult to manage, with waiting times of between 4 and 14 days. In informal discussion, Graham (Practice Manager at Practice 5) suggested that this led patients to frame problems as urgent inappropriately. This lack of routine appointments frustrated patients: "I need to know that I'm going to be ill about two weeks in advance" (Rebecca, patient, GP practice 4). Additionally, some patients felt they added an unnecessary and potentially risky layer to access.

they will ask a lot of question and then basically then they just turn around and say I need to see a doctor... If you go to your doctor to make an appointment, the bottom line is, right, "We'll give you a call back within an hour." Right, within an hour you could die. (Jackson, a 56 year old patient at GP Practice 2)

An emphasis on telephone triage also had the potential to inhibit continuity of care or fulfilment of patient preferences. For example, stated preferences for a particular GP, or with a GP who was female, could not be met in some practices.
Weekend and evening appointments and 'walk-in' (ie, no appointment) clinics had been implemented by some practices to meet demand. Demand for appointments at walk-in clinics was very high, putting pressure on facilities: in practice 4 we observed 26 patients in the queue within 10 min of doors opening, and there were 47 people in the waiting area before 09:00. Extended hours access also did not always work as intended. Practice 5 had evening and weekend access, ostensibly to facilitate access for working people:

I think sometimes it's not necessarily busy with the people that maybe need it: people that are working away, that work full-time, that was what it was intended for. But because we've got into a stage where patients couldn't see their doctor for six days, but there was a Saturday morning available, they go, "Oh yes I'll have that." (Laura, patient services manager, GP practice 5)

GP practice 4 had a higher number of working-age patients than other practices, and lack of appointments outside of the working day was noted by three patients during the interview.

\section{Communication and talking on the telephone}

Practices felt under great pressure: "even if we worked seven days a week, 24 hours a day, we will never meet demand" (Emily, GP, GP practice 2), and the telephone had become the instrument of demand management. Whereas practices saw this as beneficial ("it is pretty much the only way to deal with it [demand]," Sadiq, GP, GP practice 6), patients and carers interviewed expressed ambivalence about reliance on the telephone. Many appreciated that it could speed up access but also had a disinclination to speak with clinical staff by phone. The morning telephone rush could be problematic; "some people miss out "cos there are so many people calling at the same time" (Faith, parent, GP practice 5). Critically, reliance on the telephone had the potential to lead to inequitable access for some groups.

Patients with English as an additional language could be particularly disadvantaged by the telephone's dominance, and we observed notable variation in practice between GP practices (box 4), which appeared to drive some ED attendance (practice 1, box 4). Aisha, parent of a young child at GP practice 6, expressed frustration at what she felt was a convoluted process of accessing care (via telephone triage), and that the outcome was often not worth the effort: "I'm struggling with my English, it's not very good, sometimes you don't know which words you need to use when you are ill. So when you can't explain they say, 'You don't need to come here. Just get Paracetamol or Ibuprofen."'

Other patients described a general preference for speaking in person, for example Sam (patient at GP Practice 2) struggled to get his point across over the telephone, saying "you're not getting across exactly like sort of like what you wanna say, and sometimes maybe 
Box 4 Contrasting examples of responding to patients with English as an additional language (observation field notes)

\section{Facilitating access}

Practice 2: A couple, who appeared to be Eastern European, comes to the reception desk to say that it was past their appointment time but they had not been called. It turned out that they had not checked in when they arrived, as they did not understand that they needed to do this. Tracy responds by sending the doctor they were supposed to see a message to explain the situation and see if she could fit them in late and she also explained to the couple what to do next time they came for an appointment.

Practice 6: A man comes to Sharon with a 4-week-old baby asking about a BCG. Sharon takes him over to the community services desk. It looks like the man with the baby is having some language problems. Sharon asks what language he speaks and then sends for a colleague who speaks Arabic to come and help. Sharon, to Arabic-speaking colleague who has now arrived in reception, "This poor gentleman has been sent round the houses," and then she proceeds to explain what the issues are as she understands them. He will be sent another appointment for a BCG by community services, and then needs an 8 -week check (the original BCG appointment was missed). Sharon is telling someone she will book an interpreter for an Arabic-speaking man... Sharon is saying "Sorry you have been messed about" to the Arabic-speaking man.

Inhibiting access

Practice 1: The last walk-in appointment for today is given out at 16:31. The next man to arrive does not have English as a first language and talks about a 'point' in his thigh. Lead receptionist Mary tells him that they have no appointments left and suggests that he call 111. He does this on his mobile phone from the waiting room but he doesn't seem to manage to speak to anyone. Mary suggests that he can come back tomorrow morning and he will be able to sit and wait, or he can go to A\&E if it gets too bad in the interim.

Practice 4: At 12:24 Beth comes in with a query. A man says he has not been called but the screen is showing him as having been called at 12:00. English is not his first language. Is it something about a sick note? No-he wants to talk to doctor to see what was wrong. Doesn't want to just go back to work. He still wants an appointment to check his health. He is told to phone at 08:30 tomorrow to get an appointment. I don't think he is clear on the instructions he has been given, plus phones were very busy at 08:30, phones were more challenging when English is not a first language, and he wasn't told about the possibility of coming to the downstairs desk from 08:00 on.

like even like the wording's probably not right and that causes confusion". Although only accounting for a small proportion of the patient population, those with hearing difficulties and deaf patients were also constrained by the reliance on telephones:

Practice 2 field notes: A man at the desk is saying "Very peculiar I can't see the doctor." There seems to have been a misunderstanding and he thought he was supposed to come in to see the doctor today but he does not seem to have an appointment. He is getting upset. It seems that he does not have a phone for the doctor to call him back. The receptionist says that she will go and ask the doctor he thought he was seeing. A little later I hear the man say that he is deaf and that he was told two weeks ago by the doctor to come in. He has been told that if he sits and waits Dr Emily will see him but they cannot tell him what time. He is not happy. He says it was Dr A who told him to come. "You make me crazy here. I can't phone, I come and you tell me it is full. I came last week. Any doctor, any week. When will I be able to book a doctor."

\section{Is it an emergency?}

All GP practices had a proportion of same-day appointments categorised as 'urgent' or 'emergency' appointments, both face to face and telephone. Urgent requests would always be met, usually via GP telephone triage. It was evident in interviews and observation that patients and staff often understood these terms differently, leading to frustration and confusion. Staff claimed that some patients sought urgent appointments inappropriately: "They know how it works a little bit, so if there's no appointments then they'll make up that's its urgent" (James, receptionist, GP practice 1). Staff also attributed the demand for urgent appointments to cultural and language differences:

I suppose a big thing that plays a factor with the language barrier is that a lot of patients don't really understand the terms "urgent" "routine". A lot of them use the word "emergency," "It's an emergency," and what they actually mean is - because emergency to us in healthcare is 999, it's a real emergency whereas what they mean is that their child might have a high temperature. (Charlotte, reception manager, GP practice 2)

Long wait times for routine appointments led patients to frame their need as urgent when they otherwise might not. Mo, a patient at GP practice 2, reflects, "When you needed to speak to a doctor, what do you define as urgent or not urgent, you know?... even if it was the next day, but a week is a bit much."

'Urgency' was negotiated between patients and staff. Reception staff often supplemented the word 'urgent': "We've only got medically urgent I'm afraid," "And it is definitely medically urgent?", or using a timescale: "Is it urgent for today?" This then required patients to 'self-triage': "I sort of say, 'Well it's not an emergency-emergency, but I could do with being seen in the next day or so" (Sharon, patient, GP practice 5). Some patients appeared uneasy with defining their request for an appointment as an 'emergency', and conversely others felt that receptionists should take requests at face value: "I should know in myself that there is an issue with my mental health and I need to see somebody sooner rather than later, but I don't want to go into a deep rooted conversation with the receptionist (Rebecca, patient, GP practice 4).

Relatedly, patients/carers sometimes perceived a difference in how they and health care providers viewed the urgency or seriousness of a problem. Parent Liang (GP 
Practice 1) took his young daughter to a local ED four times over a four day period, following an intial GP consultation (see also Mehreen's story, Box 5):

We also go to GP, but I think the GP here, maybe they have a different way to we think. We think there may be a problem; they said it's OK, it's not a problem

\section{Out-of-hours care}

Complexity within the wider system, particularly around out-of-hours $(\mathrm{OOH})$ care, could also influence ED use. There was largely a lack of clarity around where to access $\mathrm{OOH}$ care, and there was a widely held view that GP care was only available within practice opening hours. In interviews patients often described not seeking care from primary healthcare prior to the index ED attendance: "I never thought of it" (Sylvia, patient, GP practice 3). Some were aware of the non-emergency $\mathrm{OOH}$ telephone line 'NHS 111', but did not know that this was a route to $\mathrm{OOH}$ GP care. For other patients, previous experience and assumptions about the quality of $\mathrm{OOH}$ care precluded it from being considered a source of help. Gemma (patient, GP practice 4) had taken her daughter to appointments with $\mathrm{OOH}$ GPs but felt that they had focused on irrelevant symptoms. She reflects, "We completely lost hope in the out of hours doctors." Similar to GP telephone triage, some patients viewed NHS 111 as an unnecessary layer of interaction, "you've taken all this 45 minutes or half an hour answering their questions, and then you go to the A\&E and they start with the forms" (Faith, Patient at GP Practice 5). Other participants, particularly those with long-term conditions, found the lack of information available to $\mathrm{OOH}$ doctors problematic:

it's an emergency appointment, and I'm in pain, and I'm looking for something to help... she was asking me all these questions about, you know, drug seeking and am I addicted and how long have I been taking these drugs? And she hadn't read the notes that led to that. (Emma, patient, GP practice 1)

In contrast to $\mathrm{OOH}$, experiences in the ED or using the NHS 999 emergency telephone number were largely positive. When asked what he would do about accessing $\mathrm{OOH}$ care in future, Fadil (patient, GP practice 2) says, "To be honest with you, I'll call 999."

Practice staff felt that a lack of awareness of $\mathrm{OOH}$ services drove ED use: "I don't think a lot of patients are aware of out of hour's services. I think if they were then A\&E wouldn't be so snowed under" (Michelle, receptionist, GP practice 1). Practices did not seem to feel responsible for promoting $\mathrm{OOH}$ care: "I'm not sure what we actually do, other than have a phone message" (Sadiq, GP, GP practice 6).

\section{Perceptions about level of care accessible at GP practice}

Some patients who had attended the ED described their ED attendance as the fastest route to appropriate care. Grace (patient, GP practice 4) describes it as "cutting out the middle man," drawing on experiences of accessing care to contextualise this:

I wouldn't necessarily have rung a GP surgery because I think they probably would have told me to go to A\&E. I guess I'm second guessing myself, but in my head I think that when I try, you know, to get appointments on a day to day basis they generally don't have appointments, and if there was anything wrong they would probably refer me to A\&E, so it's kind of a bit like cutting out the middle man.

Some patients described being dissatisfied with care and questioned their GP's competence, or felt that the ED could offer them a level of specialist skill unavailable in primary healthcare. The ED provided a level of reassurance that some patients thought would not be possible in primary healthcare: "it wasn't very nice being linked up to the ECG machine and having needles stuck in me, but felt like there was a lot more investigation done" (Rebecca, patient, GP practice 4). Mitch (patient, GP practice 4) had a painful, swollen spot on his back that he thought might be an infected insect bite. Unlike most other participants, he had consulted the GP prior to attending the ED. He anticipated that the GP would want to lance the lump but was instead given antibiotics. Mitch was sceptical about whether these would work: "I wasn't given any sort of advice going forward." Subsequently, as the pain and swelling continued, he decided to go to the ED:

there probably was an alternative but I just thought to myself, "I wanna get this sorted," and I thought the best way to do it was to go to the A\&E

Despite babies and young children having preferential access to GP care (eg, children under 2 offered same-day appointments), parents/carers could feel that their views were disregarded by GPs and perceive that they received a better quality of care in the ED. Risk perception dominated parent and carer accounts (Mehreen's story, box 5), so the ED was seen as more appropriate when they viewed problems as urgent.

\section{DISCUSSION}

Patients seeking care at the ED often doubted primary healthcare's capacity to respond to 'urgent' problems. This belief results from cumulative past experience of care-seeking. Dimensions of access to primary healthcare were implicit in all patient accounts of ED use, and observation of practice evidenced these. Different dimensions interacted with one another and with other features of primary healthcare such as relational continuity. We found that GP practices had complex appointments systems that had often evolved incrementally and reactively, with new approaches 'bolted on' to try and manage demand. Patients found them obscure and were mistrusting of them; reception staff were required to help patients navigate appointments, which privileged tacit knowledge and expertise. Although increasing reliance on the 
Box 5 Perspectives of urgency in a Patient story: Mehreen

Mehreen's 18-month-old son was born 10 weeks preterm and spent time in neonatal intensive care. Mehreen felt that the decision to go to the emergency department (ED) the first time she attended with her son (for 'very severe colic') was influenced by her experiences at neonatal intensive care unit:

When he get discharged on that time they said like, "He is premature. If he has any problems straight away you can come into hospital."

More recently, Mehreen's son developed a fever that she managed at home with paracetamol for a few days. The fever wasn't responding to paracetamol and she went to the ED, where "they just gave the Ibuprofen to him." Two days after returning home, her son developed another fever and she took him back to the ED. This time they investigated to see if there was an infection (urine sample, X-ray, blood test), but no underlying cause was found and the fever diminished while they were at the ED. Mehreen contrasts primary healthcare with the ED; she feels that in both places she is treated 'nicely' but that the quality of care and availability of equipment to investigate problems in the ED are better:

It is different because in the hospital there are really very - give very good - provide very nice care to my baby

Mehreen says that she didn't think to contact her GP because her son's fever was always at night, but her narrative suggests factors that influenced where to seek help other than GP availability. For example, she felt that the call back system does not lead to timely care, and this is especially important in the context of young children:

We have to wait for the doctor's call, because sometimes it's really very emergency and we have to ring to the GP in the morning time because they don't give any appointment if we ring at 12 o'clock, but if we ring before 80 'clock or 9 o'clock then they give the appointment on the same day. Yeah so I don't like that thing: they need to improve it... Like if we had any emergency at one o'clock, they don't give any appointment on the same day. That's why we prefer go the emergency, because we know the kids are very important in everyone's life.

Along with an expectation that she won't get a timely GP appointment, especially if she calls later in the day, Mehreen feels that concerns about her baby are often dismissed or minimised:

If we went to the GP I don't think so they bother anything... the GP they just said like, "There is not any problem, your kids are happy, there is not anything to worry about it." Because we are mums so we definitely worried about our babies' lives... I know they just give Paracetamol.

telephone (for booking appointments or for triage, for example) ostensibly helped patient through the flow, and was favoured by some patients, it could also contribute to inequity in access. The telephone potentially disadvantaged particular patient groups, including those with language differences and hearing impairments. The early morning 'phone lottery' for same-day appointments was a source of frustration for reception staff and patients. Within primary healthcare more broadly, $\mathrm{OOH}$ care appeared detached from general practice, and at a wider system level the ED could be viewed as a way to "cut out the middle man' and access appropriate care in a straightforward manner.

It is apparent from our data that access is not merely about availability of GP appointments, but includes a diversity of concerns, such as whether methods of accessing care are simple and reliable. Decisions about where to seek care have been conceptualised as "depth decisions" (p24:65) complex, multistage decisions that hold potentially significant implications. Our data support the concept of candidacy, where eligibility for healthcare is formed via negotiation between the patient and healthcare service/provider. ${ }^{25-28}$ For interviewed patients, perceptions of a mismatch between GPs' view of candidacy and their own could influence decisions to seek care elsewhere (cf, Kovandžić $e t a l^{27}$ ). Furthermore, our data show how patient decision making is informed by cumulative past experience, that is, there is a recursive nature to access. ${ }^{27-29}$ As a result, seemingly minimal past experiences such as having to wait in a telephone queue to speak with GP reception staff or a long wait for a routine appointment can inform a global view of primary healthcare as an inappropriate source of urgent care at a later point. This may help account for the relatively low proportion of patients in our study who sought help from primary healthcare prior to their index ED attendance(s), which corresponds with other studies. ${ }^{30}$ The multiplicity of innovations to enhance access and the way they have been implemented has been described as complicated, resulting in greater system complexity and overlapping services. ${ }^{31}$ It was clear in our study that this complexity was a significant implicit factor in ED use, and had consequences for continuity of care, as described elsewhere. ${ }^{32} 33$

Our data have implications for practice and policy. Within individual GP practices (and within primary health care collectively), there is unlikely to be a 'one size fits all' approach to access. Practices in our study were attempting to meet the needs of the majority of their patient population, but in doing so developed complex appointments systems that could inadvertently disadvantage some groups-often those who experienced greater obstacles to accessing care. Priority should be given to simplifying appointments systems and communicating mechanisms to patients, which can help build trust and facilitate equity of access. The burden for negotiating access to care largely falls on GP receptionists, and the complexity of their role demands recognition and adequate support. ${ }^{34}$ Active and open engagement with patient perspectives will help General Practice move beyond notions of 'inappropriate' patient-led demand that risk foreclosing avenues for improving access.

ED departments themselves also have a role in deflecting patients back to primary healthcare. The reactive and cumulative approach most practices in our study took to appointments systems reflects the huge pressures they face due to a combination of demand that substantially exceeds supply and attempts to respond to frequent changes in healthcare policy. Our analysis shows that it is not availability of appointments alone that influences 
decisions to attend the ED. This supports the argument that initiatives that focus on availability of care, such as Extended Access, are unlikely to be a panacea for rising rates of ED use. ${ }^{8}{ }^{9}$ Instead, a holistic approach that incorporates differing dimensions of access ${ }^{35} 36$ and accommodates the complexity of patient decision making is needed.

There were limitations to this study that could be addressed in future research. Recruitment of patients and carers was difficult at times; practices had distinct approaches to recording and using ED data relating to their patients, and there was poor response at some practices that required multiple sampling over time to secure interviews with a sufficient number of patients/carers. Although we believe that sufficient data were collected to develop a comprehensive and credible account of patient experience, returning to practices for theoretical sampling of additional patients was not possible. More detailed investigation of the experiences of patients with English as an additional language and with patients aged 18-25 would provide insight into the distinctive experiences of these groups. Our study was not designed to test if the ratio of GPs to patients at a practice (one marker of provision of consultation availability) could influence the findings, but there is a possibility that a lower number of GPs for a patient population at a given practice could exacerbate problems with appointment availability. Additionally, ethnographic study of $\mathrm{OOH}$ care provision is needed to evaluate its relationship with ED use and with in-hours care.

\section{Conclusion}

We believe that this is the first ethnographic study to purposely explore the ways in which access to UK general practice influences use of the ED. This article challenges the idea of 'patient demand' as primary driver for rising ED use and turns the lens to interactions in primary healthcare. We propose that help-seeking at the ED can be a rational response to care-seeking when access to primary care is experienced as complicated and opaque, and where previous engagement has failed to meet needs.

Contributors FM was lead researcher on the study and contributed to design, fieldwork and analysis/interpretation, as well as drafting the manuscript and revisions. EB was a researcher on the study and conducted fieldwork and analysis/ interpretation, and made a significant contribution to manuscript revisions. LW and KC contributed to study conceptualisation, design and interpretation of data, and made a significant contribution to manuscript revisions. DL contributed to study conceptualisation and interpretation of findings, and made a significant contribution to manuscript revisions. AH, PT, CS and RM contributed to interpretation of the data and provided feedback on the manuscript. SP was the principal investigator for the study; she led the design, supervised the project and its staff, and made a significant contribution revising the manuscript. All authors approved the final version of this manuscript

Funding This work was supported by the National Institute for Health Research School for Primary Care Research, grant number FR6/168. DL is funded by the NIHR Oxford Biomedical Research Centre.

Disclaimer The views expressed are those of the authors and not necessarily those of the NHS, the NIHR or the Department of Health.
Ethics approval NRES Committee West Midlands - Coventry \& Warwickshire.

Provenance and peer review Not commissioned; externally peer reviewed.

Open Access This is an Open Access article distributed in accordance with the Creative Commons Attribution Non Commercial (CC BY-NC 4.0) license, which permits others to distribute, remix, adapt, build upon this work non-commercially, and license their derivative works on different terms, provided the original work is properly cited and the use is non-commercial. See: http://creativecommons.org/ licenses/by-nc/4.0/

Correction notice The article has been corrected since it first published. The Funding and Disclaimer statements have been added in.

C Article author(s) (or their employer(s) unless otherwise stated in the text of the article) 2017. All rights reserved. No commercial use is permitted unless otherwise expressly granted.

\section{REFERENCES}

1. England NHS. A\&E Attendances and Emergency Admissions 2016-17. 2016. https://www.england.nhs.uk/statistics/statisticalwork-areas/ae-waiting-times-and-activity/statistical-work-areasaewaiting-times-and-activityae-attendances-and-emergencyadmissions-2016-17/ [25 July 2016].

2. Hospital episode statistics accident and emergency attendances in England - 2014-15. Hospital Episode Statistics Analysis HaSCIC, 2016.

3. Cowling TE, Cecil EV, Soljak MA, et al. Access to primary care and visits to emergency departments in England: a cross-sectional, population-based study. PLoS One 2013;8:e66699.

4. Baker C. Briefing paper 6964: accident and emergency statistics. In: House of Commons Library, ed. London: House of Commons Library, 2015.

5. Campbell SM, Roland MO, Buetow SA. Defining quality of care. Soc Sci Med 2000;51:1611-25.

6. Murray M, Berwick DM. Advanced access: reducing waiting and delays in primary care. JAMA 2003;289:1035-40.

7. Pope C, Banks J, Salisbury C, et al. Improving access to primary care: eight case studies of introducing advanced access in England. $J$ Health Serv Res Policy 2008;13:33-9.

8. Simpson JM, Checkland K, Snow S, et al. Access to general practice in England: time for a policy rethink. Br J Gen Pract 2015;65:606-7.

9. Cowling TE, Harris MJ, Majeed A. Evidence and rhetoric about access to UK primary care. BMJ 2015;350:h1513.

10. Manchester NCG. NHS greater manchester primary care demonstrator evaluation: final report. NIHR CLAHRC Greater Manchester 2015.

11. The University of Centre for Reviews and Dissemination. Enhanced access in primary care settings. 2015.

12. Ismail SA, Gibbons DC, Gnani S. Reducing inappropriate accident and emergency department attendances: a systematic review of primary care service interventions. $\mathrm{Br} J$ Gen Pract 2013;63:e813-e20.

13. Huntley A, Lasserson D, Wye L, et al. Which features of primary care affect unscheduled secondary care use? A systematic review. BMJ Open 2014;4:e004746.

14. Harris MJ, Patel B, Bowen S. Primary care access and its relationship with emergency department utilisation: an observational, cross-sectional, ecological study. Br J Gen Pract 2011;61:787-93.

15. Cowling TE, Harris $M$, Watt $H$, et al. Access to primary care and the route of emergency admission to hospital: retrospective analysis of national hospital administrative data. BMJ Qual Saf 2016;25:432-40.

16. Tammes P, Morris RW, Brangan E, et al. Exploring the relationship between general practice characteristics, and attendance at walk-in centres, minor injuries units and EDs in England 2012/2013: a crosssectional study. Emerg Med J 2016;33:702-8.

17. Hudon C, Sanche S, Haggerty JL. Personal characteristics and experience of primary care predicting frequent use of emergency department: a prospective cohort study. PLoS One 2016;11:e0157489.

18. Koziol-McLain J, Price DW, Weiss B, et al. Seeking care for nonurgent medical conditions in the emergency department: through the eyes of the patient. J Emerg Nurs 2000;26:554-63.

19. Howard MS, Davis BA, Anderson C, et al. Patients' perspective on choosing the emergency department for nonurgent medical care: a qualitative study exploring one reason for overcrowding. J Emerg Nurs 2005;31:429-35. 
20. Durand AC, Palazzolo S, Tanti-Hardouin N, et al. Nonurgent patients in emergency departments: rational or irresponsible consumers? perceptions of professionals and patients. BMC Res Notes 2012;5:525.

21. Göransson KE, De Waern M, Lindmarker P. Patients' pathway to emergency care: is the emergency department their first choice of care? Eur J Emerg Med 2013;20:45-50.

22. Gordon J, Sheppard LA, Anaf S. The patient experience in the emergency department: a systematic synthesis of qualitative research. Int Emerg Nurs 2010;18:80-8.

23. Marco CA, Weiner M, Ream SL, et al. Access to care among emergency department patients. Emerg Med $J$ 2012;29:28-31.

24. Murphy AW. 'Inappropriate' attenders at accident and emergency departments I: definition, incidence and reasons for attendance. Fam Pract 1998;15:23-32.

25. Dixon-Woods M, Cavers D, Agarwal S, et al. Conducting a critical interpretive synthesis of the literature on access to healthcare by vulnerable groups. BMC Med Res Methodol 2006;6:35.

26. Dixon-Woods M, Kirk M, Agarwal S, et al. Vulnerable groups and access to health care: a critical interpretive review. 2005.

27. Kovandžić M, Chew-Graham C, Reeve J, et al. Access to primary mental health care for hard-to-reach groups: from 'silent suffering' to 'making it work'. Soc Sci Med 2011;72:763-72.
28. Hunter C, Chew-Graham C, Langer S, et al. A qualitative study of patient choices in using emergency health care for long-term conditions: the importance of candidacy and recursivity. Patient Educ Couns 2013;93:335-41.

29. Rogers A, Hassell K, Nicolaas G. Demanding patients? analysing the use of primary care. Open University Press: Oxford, 1999.

30. Singh S. Self referral to accident and emergency department: patients' perceptions. BMJ 1988;297:1179-80.

31. Tan S, Mays N. Impact of initiatives to improve access to, and choice of, primary and urgent care in the England: a systematic review. Health Policy 2014;118:304-15.

32. Rose KD, Ross JS, Horwitz LI. Advanced access scheduling outcomes: a systematic review. Arch Intern Med 2011;171:1150-9.

33. Campbell SM, Kontopantelis E, Reeves D, et al. Changes in patient experiences of primary care during health service reforms in England between 2003 and 2007. Ann Fam Med 2010;8:499-506.

34. Hammond J, Gravenhorst K, Funnell E, et al. Slaying the dragon myth: an ethnographic study of receptionists in UK general practice. Br J Gen Pract 2013;63:177-84.

35. Gulliford M, Figueroa-Munoz J, Morgan M, et al. What does 'access to health care' mean? J Health Serv Res Policy 2002;7:186-8.

36. Boyle S, Appleby J, Harrison A. A rapid view of access to care. London 2011. 